\title{
Datos abiertos, su apuesta económica y la promesa política
}

\author{
Eréndira Sarahí Pérez Ponce | Máster en Dirección y Gestión Pública, Universidad de Granada
}

URL de la contribución <www.iaph.es/revistaph/index.php/revistaph/article/view/3955>

Entre las más recientes reformas de modernización de las administraciones públicas se encuentran las que convergen en un cambio de relaciones entre gobiernos y gobernados, la apertura de información, así como la incorporación de elementos técnicos y tecnológicos en este proceso de intercambio. Aunque esta innovación no resulta paradigmática, pues no es un rompimiento con las teorías sociológicas o politológicas, sí es la tendencia de gestión, desde las ópticas administrativa y económica, en las agendas gubernamentales a nivel internacional desde la publicación de The 8 Principles of Open Government Data ${ }^{1}$ en 2007 y el Memorandum de la Open Government Initiative signado por el presidente estadounidense Obama en 2009. Así como la promoción de la Alianza para el Gobierno Abierto (AGA) de 2011 o más difundido en la literatura especializada como OGP (Open Government Partnership).

Si bien transparencia, e-goverment y gobernanza habían trazado algunas pautas para la conceptualización de Gobierno Abierto (GA), como lo son: la publicidad, la co-relación, la política "desde abajo", la rendición de cuentas, la participación ciudadana, digitalización, entre otras; el enfoque precursor de esta innovación gubernamental o propiamente estatal (OZSLAK, 2015: 45) tiene un énfasis en su potencialidad para crear valor público. Los datos abiertos (DA) se inscriben en esta lógica, no como sinónimo de GA, sino como elemento base para su existencia.

Aunado a lo anterior, debido a la especialización de la labor burocrática, se expone también la necesidad de "abrir" la información mediante la simplificación o adecuación del lenguaje; ello, conjuntamente con las labores tecnológicas que faciliten su accesibilidad y entendimiento para la ciudadanía, son formas de lograr los postulados de apertura gubernamental (SANDOVALALMAZÁN, 2016: 298).
La finalidad de abrir los datos públicos va más allá de una primera vista de publicitarlos en un portal gubernamental en Internet, del derecho al acceso, a la publicación de información de la agenda o políticas gubernamentales, del cumplimiento con una Ley de Transparencia o de revisión de informes de actividades, asimismo "no sólo implica la publicación sistemática de información en un formato que facilite la reutilización sino que apuesta por los estándares abiertos para promover el acceso de la sociedad civil a los datos públicos así como para facilitar la interoperabilidad de los sistemas de información del gobierno" (GASCÓ, 2014: 14). Es decir, la apuesta es por una plataforma de confluencia y co-participación en la generación y retroalimentación de información, llamada también reutilización de datos, entre actores en el espacio público en términos de interacción a nivel horizontal para generar un nuevo producto.

La reutilización de la información gubernamental pública es el espíritu con el cual la Unión Europea, y consecuentemente España, ha impulsado la legislación en la materia (Directiva 2003/98/CE o la Ley 18/2015 de Reutilización de información del sector público -RISP-), pues la generación de información per se sola no implica la creación de un valor, sólo puede potenciarlo. Y es en esta oferta que "la digitalización y los datos culturales son la materia prima de la economía de la información, y no sólo un derecho educativo" (FERRER-SAPENA; PESET, 2012: 195), lúdico, cultural, asociativo o de identidad.

Los datos, cifras, informes, archivos, historiales, documentos originados en la labor administrativa que en su conjunto se presentan como output, requerirán tanto de ser útiles para los externos, como mantener vías y medios para que sean manipulados e intercambiados, lo que será un nuevo input para la toma de decisiones con base en estos macrodatos (o Big Data), como lo puede ser el entendimiento de gustos del público en activida- 


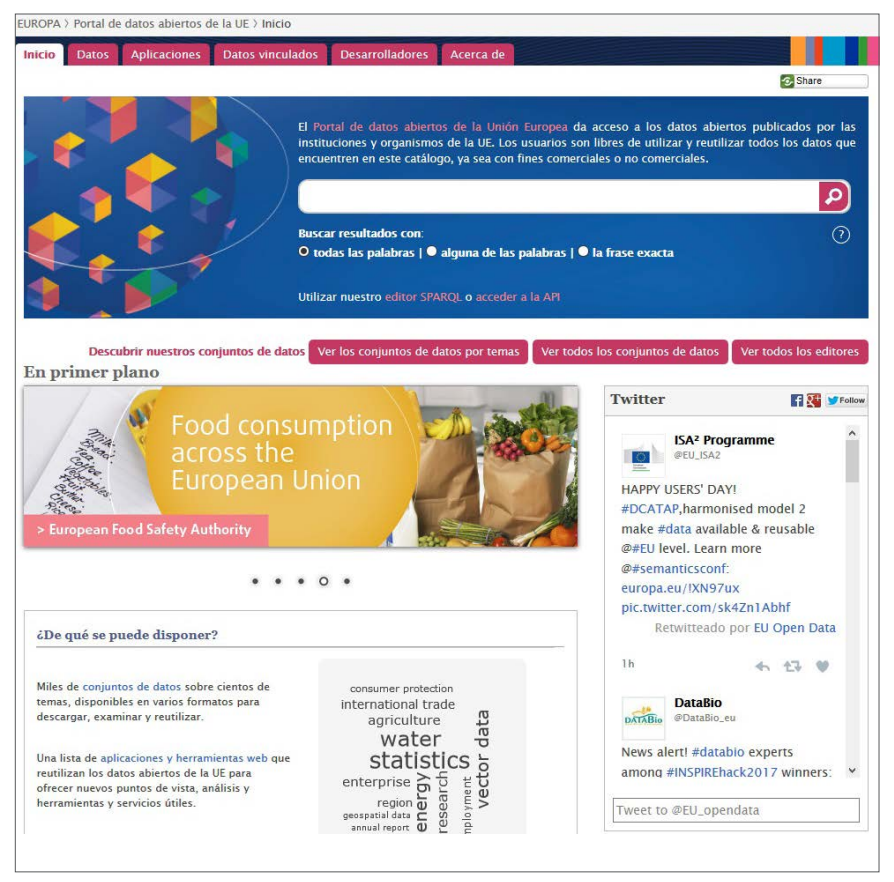

Portal de datos abiertos de la Unión Europea (http://data.europa.eu/euodp/es/ home/)

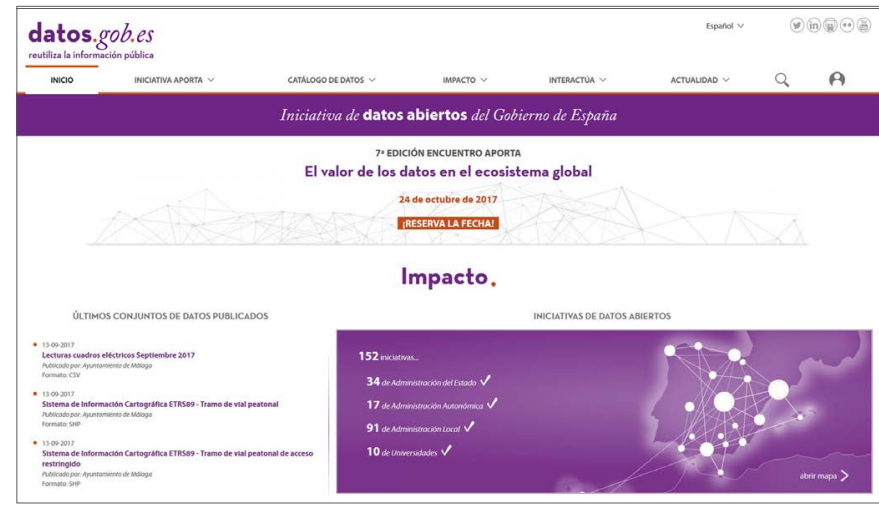

Iniciativa de datos abiertos del Gobierno de España (http://datos.gob.es/)

des culturales de la localidad y su consecuente análisis para procesos de planificación o toma de decisiones.

En el plano de la cultura en la esfera pública, como no podría ser de otra forma, se vive un crecimiento prometedor y aún sin fronteras previsibles por parte de terceros, empresas que han vislumbrado en esta apertura de información la posibilidad de reajustarla y hacerla de utilidad para intereses específicos de la ciudadanía. Un caso típico es Agenda Oberta de Cataluña, que no sólo se alimenta de DA, sino que es un sitio donde se encuentran y clasifican todas las actividades de corte cultural y artístico, además de tener la opción de republicar y reutilizar. Los principales interesados en hacerse con este conocimiento de actividades y comportamientos de públicos específicos, con la finalidad de ajustar su oferta, son los negocios de ocio, alimentos, diversión o servicios de transporte, turismo o acomodación.

Asimismo, la tendencia en las administraciones públicas de cultura a nivel europeo apuestan por extender los límites de la apertura respecto a obras artísticas (véase el caso de La lechera amarilla del Rijksmuseum), datos culturales, en la titánica digitalización de archivos históricos, así como mejorar sus plataformas y ampliar sus capacidades de intercambio con internautas, empresas e incluso otros gobiernos. Siguiendo esta línea, la Junta de Andalucía y, en concreto, su Consejería de Cultura ha desarrollado un avance importante al respecto, como lo demuestra el Reconocimiento 4.0 Internacional (CC BY 4.0). Lo que se traduce en la posibilidad de crear, pegar, redistribuir, manipular y mezclar los datos con cualquier fin. Estos datasets públicos podrían clasificarse, también en la escala de las 5 estrellas de Berners-Lee, con un 4. Dejando como margen para su evolución el fortalecimiento y aprovechamiento del Linked Data o llamada "web semántica", que consiste en vincular los datos a otros (de cualquier parte del mundo) para proporcionarles un contexto (ORTIZ DE ZÁRATE, 2014: 92-93).

Concluyendo, se retoma la necesidad de repensar las promesas política y económica de la propuesta internacional de DA, derivada de una lógica particular de gestión gubernamental, puesto que en la realidad no ha impactado de forma profunda al general de la ciudadanía, solo en sectores organizados. En temas de la agenda política, los detractores de esta tendencia señalan que esta hiper-información no nos forma más en ciudadanía, ni vuelve a las personas más partícipes, ni cultas. El "enjambre digital", lejos de ampliar la participación, implica una despolitización de la sociedad al 
percibir lo que un algoritmo muestra en una burbuja personalizada de imágenes del mundo con las que se está identificado, desintegrando así la esfera pública, la conciencia pública, o la crítica (HAN, 2014).

Ahora bien, en el sentido de la apuesta económica de la apertura de datos como generadora de emprendimiento, de un mercado de conocimiento valorado en la Unión Europea en 272000 millones de euros en 2015, según comunicado de prensa de la Comisión Europea de 10 de enero de 2017; siendo los operadores privados quienes tienen acceso a recursos que los diferencian del resto de la población y quienes generan valor a una información pública, dilema en términos de igualdad de oportunidades.

Finalmente, se comenta que todas las interacciones donde gobierno y sociedad convergen para generar beneficios resultan positivas, no obstante la participación, el conocimiento y el acceso siguen siendo las faltas en la edificación de un proceso donde se requieren dos partes (o más) para el intercambio, que es la clave en esta ecuación. Aun así, el aumento de las capacidades técnicas, la creatividad de empresas, la revolución dentro de las administraciones públicas y la constitución de organizaciones críticas y observantes vislumbran un sendero promisorio donde los postulados de DA y GA sean garantes y posibles para cualquier ciudadano del mundo.

\section{NOTA}

1. Para que se consideren abiertos, los datos deben cumplir con los siguientes requisitos: completos, primarios, actuales, accesibles, procesables, no discriminatorios, no propietarios y sin licencia (O'REILLY, 2007).

\section{BIBLIOGRAFÍA}

- FERRER-SAPENA, A.; PESET, F. (2012) Reutilización de datos culturales. Anuario ThinkEPI, v. 6, 2012, pp. 193-196

- GASCó, M. (2014) Qué es el gobierno abierto (y qué no lo es). En CALDERÓN, C. (coord.) Guía Práctica para abrir Gobiernos Manual de "Open Government" Para Gobernantes y Ciudadanos. Instituto Universitario de Investigación Ortega y Gasset, 2014, pp. 11-22 <http:// www2.congreso.gob.pe/sicr/cendocbib/con4 uibd.nsf/ F0CE9C642E7BC17205257F1400075324/\$FILE/gēt_file.pdf> [Consulta: 6/6/2017]

- HAN, B-C. (2014) En el enjambre. Barcelona: Herder Editorial, 2014

- LEY $\mathbf{1 8 / 2 0 1 5}$ por la que se modifica la Ley $37 / 2007$ sobre reutilización de la información del sector público. Boletín Oficial del Estado, n. ${ }^{\circ}$ 164, 10 de julio de 2015, pp. 57436-57450 <http://www.boe.es/diario boe/txt.php?id=BOE-A-2015-7731> [Consulta: 6/6/2017]

- ORTIZ DE ZÁRATE, A. (2014) Diseño de una iniciativa de apertura de datos públicos. En CALDERÓN, C. (coord.) Guía Práctica para abrir Gobiernos Manual de "Open Government" Para Gobernantes y Ciudadanos. Instituto Universitario de Investigación Ortega y Gasset, 2014, pp. 67-101 <http:// www2.congreso.gob.pe/sicr/cendocbib/con4_uibd.nsf/ F0CE9C642E7BC17205257F1400075324/\$FILE/gēt file.pdf> [Consulta: 6/6/2017]

- O'REILlY, T. et ál. (2007) The 8 Principles of Open Government Data. Sebastopol, CA: Open Government Working Group Meeting, 2007 <https://opengovdata.org/> [Consulta: 01/06/2017]

- OZSLAK, O. (2015) Ideas sobre Gobierno Abierto: el rumbo de los conceptos. En LUNA PLA, I.; BOJÓRQUEZ PEREZNIETO, J. A. (Coord.) Gobierno Abierto el valor social de la información pública. Instituto de Investigaciones Jurídicas, UNAM, 2015 <http://biblio.juridicas.unam.mx/libros/ libro.htm?|=4016> [Consulta: 13/06/2017]

- DATOS Abiertos. Portal de la Junta de Andalucía. 2017 <http://www.juntadeandalucia.es/datosabiertos/portal/dataset/ estadisticas-consejeria-cultura> [Consultas: 03/06/2017-14/07 /2017]

- SANDOVAL-ALMAZÁN, R. (2016). Gobierno Abierto: conceptos, cifras y futuros. En GIL-GARCÍA, J. R.; CRIADO, J. I.; TÉLLEZ, J. C. (ed.) Tecnologías de Información y Comunicación en la Administración Pública: Conceptos, Enfoques, Aplicaciones y Resultados. México: INFOTEC, 2016, pp. 293-318 